\title{
Factores relacionados con la elección de la especialidad en Medicina
}

\author{
Factors related to the choice of specialty in Medicine
}

La elección de una especialidad de parte del médico, depende de muchos factores. Quizás, el interés por la especialidad sea el factor más importante, sin embargo, pueden influir factores demográficos, la oferta y demanda de las especialidades, factores extracurriculares, entre otros.

En Perú, a partir de la década de los '90 se observó un incremento progresivo en la proporción de mujeres, en los estudiantes de la carrera de Medicina, siendo en la actualidad mayor del 50\%. Un estudio realizado por Llanos F. et al. (1), en escolares del último año de colegios de Lima, entre estatales y privados, conformada por $70 \%$ de varones, mostró que sólo el 18,6\% deseaba estudiar medicina, y tener un familiar profesional de salud, una experiencia previa buena con un médico y el conocimiento de la duración de la carrera estuvieron asociados a la elección; el 86,1\% la consideraron una carrera larga.

Querido SJ, et al. (2), en una revisión sistemática encontraron que los factores que influyen en la elección de una especialidad, pueden ser clasificados en cinco categorías: características de la escuela de Medicina (pública o privada, estructura curricular), características del estudiante (demografía, personalidad), los valores del estudiante (preferencias personales), las necesidades a ser cumplidas durante la especialidad (ingreso, prestigio, tiempo libre) y la percepción de la especialidad (experiencias curricular y extracurricular).

El estudio publicado en este fascículo por Cedillo LPG et al. (3), realizado en internos de Medicina de dos universidades privadas de Lima, Perú, encontró que la elección de psiquiatría como especialidad se asoció con: personalidad sanguínea; extroversión y ser emocionalmente estable, y no encontró relación con sexo, tener parientes con carreras afines al área de la salud mental, presencia de psicopatología, ni con la percepción favorable del dictado del curso de Psiquiatría.

Durante la carrera, el estudiante se nutre de la orientación y estructura de la escuela a la que pertenecen; las rotaciones clínicas con mayor o menor carga hacia rotaciones quirúrgicas o médicas, así como, el diseño curricular (tradicional o basado en problemas) pueden afectar la elección (4). Dentro de las características del estudiante se menciona la personalidad; existen varios estudios en los que se evalúa la influencia de la personalidad en la elección de una especialidad médica. El modelo de los cinco grandes factores provee un marco conceptual para describir la personalidad de una forma clara; incluye características afectivas, de experiencia y de motivación y utiliza las dimensiones de extroversión, apertura al cambio, responsabilidad, amabilidad y neuroticismo (inestabilidad emocional) (4).

Gutierrez-Cirlos C, et al. (4), en su revisión menciona que "los especialistas en medicina interna se han descrito como rígidos, fríos, escépticos, con preferencia a trabajar con cosas más que con personas. En otros trabajos se les ha encontrado con un mayor grado de conciencia, son más organizados y persistentes, pero en general son menos extrovertidos, pues se enfocan en el mundo interno más que en la interacción social. Los especialistas en ginecoobstetricia tienden a ser más extrovertidos y con un pensamiento y juicio más sensible...son más conscientes, organizados, persistentes, escrupulosos y orientados a metas...tienen puntuaciones más bajas con relación a la apertura al cambio y a la amabilidad; los médicos familiares o los psiquiatras son más altruistas que los ginecoobstetras." La descripción de la personalidad es similar a la encontrada en el estudio de Cedillo LPG, publicado en este número. 
Además, señala: "Los pediatras tienden... más al neuroticismo, la extraversión y la amabilidad." Los cirujanos en cambio "tienen más capacidad de adaptación al cambio, son extrovertidos y abiertos. Así, los cirujanos, tienen que mostrar una importante adaptación al cambio cuando deben de dejar todo lo que hacen para atender una urgencia."

El prestigio profesional es un factor determinante para la elección de la especialidad. Algunos médicos escogen una especialidad que les da más jerarquía y prestigio; estas especialidades están orientada más a la técnica y no a la persona. Esto se puede explicar por la teoría de dominancia social. Las especialidades quedan más prestigio son cirugía, medicina interna y anestesiología, mientras que la medicina general, la psiquiatría y la geriatría se encuentran entre las de menor prestigio (4).

Lepièce et al. (5), encontró que los estudiantes con mayor orientación de dominancia social, independientemente del sexo, eligieron especialidades con mayor orientación técnica y con mayor prestigio.

En cuanto a las necesidades por satisfacer, en los últimos años, los estudiantes optan por especialidades en las que el estilo de vida y la actividad laboral son más controlables, por ejemplo, urgencias médicas, porque tienen un horario fijo de trabajo o dermatología porque las urgencias son raras, contrariamente a la cirugía u otra especialidad, en donde el estilo de vida no es controlable (4).

Finalmente, la percepción de la especialidad como las experiencias clínicas, rotaciones, el realizar procedimientos médicos y el contacto con cierto tipo de paciente están relacionados con la elección de la especialidad. También las experiencias extracurriculares como el haber estado enfermo o haber tenido algún familiar con enfermedad crónica, influyen.

Como se puede apreciar, el proceso de elección de la especialidad es complejo y aún no está completamente entendida.

Juan Miyahira ${ }^{1, a}$

\section{REFERENCIAS BIBLIOGRÁFICAS}

1. Llanos F Reyes RC, Lecca LW, et al. Percepciones de la carrera médica en escolares del último año de colegios urbanos de Lima, Perú. Rev Med Hered. 2004; 15:136-143.

2. Querido SJ, Vergouw D, Wigersma L. Dynamics of career choice among students in undergraduate medical courses. A BEME systematic review: BEME Guide No. 33. Med Teach. 2016; 38:18-29.
3. Cedillo LPG, Correa LE, De la Cruz JA. Factores asociados a la elección de Psiquiatría como especialidad en internos de medicina de dos universidades privadas del Perú. Rev Med Hered. 2019; 30(3):170-177.

4. Gutiérrez-Cirlosa C, Navejab JJ, SanchezMendiola M. Factores relacionados con la elección de una. Inv Ed Med. 2017; 6:206-214.

5. Lepièce B Reynaert C, van Meerbeeck P, Dory V. Social dominance theory and medical specialty choice. Adv in Health Sci Educ. 2016; 21:79-92.

Facultad de Medicina Alberto Hurtado. Universidad Peruana Cayetano Heredia. Lima, Perú.

Profesor Principal. 